\title{
Pattern and Outcome of Central Nervous System Infections in Suez Governorate
}

\author{
Mahmoud Sheded, MD ${ }^{1}$, Mohamed F. Hassan, $\mathrm{MD}^{2}$, Rania Kishk, $\mathrm{MD}^{3}$, \\ Wael Gabr, $\mathrm{MD}^{4}$, Amira Said, $\mathrm{MSc}^{2}$ \\ ${ }^{1}$ Endemic and Infectious Diseases Department, Faculty of Medicine, Suez University, Suez, Egypt \\ ${ }^{2}$ Endemic and Infectious Diseases Department, Faculty of Medicine, Suez Canal University, \\ Ismailia, Egypt \\ ${ }^{3}$ Microbiology Department, Faculty of Medicine, Suez Canal University, Ismailia, Egypt \\ ${ }^{4}$ Neurology department, Faculty of medicine, Mansoura University, Mansoura, Egypt
}

Corresponding Author Mahmoud Mohamed Ebrahim Sheded

Mobile: 01224337370 E mail:
mahmoudsheded@ga
mil.com

Key words: Meningitis; Septic ; Aseptic ;

Pneumococcal ; Neisseria Meningitidis; CNS infections
Background and study aim: Egypt is an endemic area with Central nervous system (CNS) infections, which associated with high complications and death rates so it is considered a medical emergency. In spite of emerging of new potent antibiotics and availability of specific vaccination accompanied with improving of medical care, morbidity rates accompanied with CNS infection remains unacceptably high. There is dramatic change in the epidemiology of CNS infection that leads to incomplete understanding of its pathogenesis which interferes with the initiation of effective is a growing need for more researches to uncover these changes. The aim of the study is to assess the pattern of CNS infections, identify the causative organisms, course and outcome of the CNS infections to implement standard management approaches and improve outcome.

Patients and Methods: One hundred twenty-four patients, recruited from Suez empirical antimicrobial treatment. There

Fever and General Hospitals with suspected CNS infection, were enrolled in this study. CNS infection was confirmed by cerebrospinal fluid results supported by clinical diagnosis and in some patients brain imaging was performed.

Results: In our study streptococcus pneumonia was the main cause of septic meningitis; males infected more than females, children were the most vulnerable group; among children Haemophilus influenzae was the commonest cause of septic meningitis. Mycobacterium meningitis was the leading cause of death among studied patient and deafness was the main neurological complication.

Conclusion: Early clinical suspicion of CNS infection and immediate management are crucial factors in reduction of the still high morbidity and mortality rates. The changes in the pattern of causative organisms must be considered when starting empiric antibiotic.

\section{INTRODUCTION}

Any infectious agents (bacteria, virus, fungus or parasite) who can access Central nervous system (CNS) can produce specific clinical syndromes as meningitis, encephalitis, brain abscess, subdural empyema, and infectious thrombophlebitis. CNS infections carry high morbidity and mortality rates [1]. septic meningitis can be lethal in 50\% of untreated cases. Moreover, 10-20\% of the survivors develop permanent sequelae as brain damage, hearing loss, and learning incapacities [2], early clinical suspicion, appropriate investigations, and quick hospitalization for management can be lifesaving [1].

Viral CNS infection is relatively uncommon [3], it infects meninges causing aseptic meningitis or infect both meninges and brain tissues producing meningo-encephalitis and rarely cause pure encephalitis [4].

Poor-socioeconomic conditions and antibiotics misuse in developing countries facilitate septic meningitis spread and generate new resistant strains [2]. Poor-socioeconomic conditions leads to poor personal hygiene, bad 
housing and negligence of general sanitation rules so facilitate spread of infectious agents. Moreover, bacteria continuously evolving new strains of pathogens resist the ordinary drugs which result from antimicrobial therapy misuse, besides the pathogens under continuous transformations evolving modern strain resist to the conventional antimicrobial agents and can elude our immune system and pass without discovery [5].

Bacterial meningitis transmission around the world has changed significantly, following the widespread use of vaccination for Haemophilus influenzae (H. influenzae) and Neisseria meningitides ( $N$. meningitides). Currently, the Streptococcus pneumonia (S. pneumonia) is most commonly organism responsible for community-acquired bacterial meningitis [1].

The causative organisms of bacterial meningitis vary by age and across regions. Improving current knowledge of bacterial meningitis causative agents' help to provide proper vaccination and the use of accurate antimicrobial medications which can halt the disease spread [6,7]. In Egypt, $N$. meningitides, was the major etiological agent for bacterial meningitis in adults [8], now S. pneumonia is the driving cause [5] and the main organism responsible for community acquired bacterial meningitis [1]. Whereas $H$. influenzae is the driving causes of bacterial meningitis in children [5].

The frequency of meningitis vary in Egypt, the hot and dry winter in Upper Egypt make meningitis less common compared to Delta [9]. Meningitis occurs mainly during winter and spring months but sporadic cases happened all over the year [8]. it affects infants and adults more than children [1] and men more than women [11].

\section{The aim of this study:}

To assess the pattern of CNS infections, identify the causative organisms, the course and outcome of the CNS infections to implement standard diagnostic and therapeutic approaches and improve outcomes.

\section{SUBJECTS AND METHODS}

This study was carried out in Suez governorate, Egypt. It was subjected to an expedited review by the faculty research ethics committee to study the pattern of CNS infections in Suez governorate, it was a descriptive prospective hospital-based. It was a conventional sample, all patients presented to Suez Fever and General Hospitals with clinical suspicion of CNS infection during the period from May 2014 till April 2016 were enrolled in this study. Using power of the study of $80 \%$ and $\alpha$-error of 0.05 , the least required sample size is 100 patients.

For each patient a complete history taking (including secio-demographic data, exact onset of symptoms and date of hospital admission to calculate the prodromal period which is the period from the appearance of symptoms till hospital admission, also the history of contact with person with similar condition, in drug history we stressed on vaccination and antimicrobial medication prior to hospital admission), Complete clinical examination, full neurological examination (the vital signs were monitored, the exact conscious level were determined, signs of meningeal irritation and increase intracranial pressure were examined and observed carefully as well as detection of any neurological deficit), radiological evaluation (brain imaging using CT or MRI) and lumber puncture were performed on all patients using aseptic techniques.

Cerebrospinal fluid (CSF) was divided into 2 tubes: the first is an empty sterile tube and the second sterile tube containing a few drops of glucose broth. The first tube was utilized for making staining smears while the second sample was used for cultures.

CSF examination involved the following: physical examination (detecting the opening pressure as normal or high and the color of CSF sample whether turbid, clear or bloody), chemical examination (measuring CSF sugar level in relation to serum sugar level, detecting the CSF protein concentration), cytological examination (it done immediately without any delay since one hour delay may leads to neurtophils lysis by about $32 \%$ of its original count, this percent may increased to $50 \%$ after 2 hours [12]). Estimating the number of white blood cells (WBC) and detecting the predominant cell subtype, also counting the number of red blood cell (RBCs), as in case of traumatic LP or subarachnoid haemorrhage (the CSF WBC count increased), Gram and Ziehlneelsen stained smears (for detection of the staining and shape of organisms), cultures for Gram negative, Gram positive and M. tuberculosis, testing and detection of the antigenic properties of the organisms using latex agglutination test.

In bacterial meningitis CSF Characterised by elevated CSF protein concentration with hypoglycorrhachia combined with polymorphonuclear pleocytosis [13], However, in immunecompromised individuals, patient with septic 
shock or systemic complications may show low CSF WBC below 100 cells/mm3, which may indicate excessive bacterial growth associated with decreased cellular immune response [6].

According to the clinical presentation and bacterial CSF cultures, our patients were classified into two types: the first group of patients with acute septic meningitis, they were 106 patients, and the second group of patients with acute aseptic meningitis, it included 18 patients [14].

The SPSS windows version 20 program was used in this study to analyze the data. Data were expressed in numbers and percentages, for qualitative non parametric variables the median percentiles were used while in quantitative parametric data the mean \pm standard deviation (SD) were used. Chi-square test also used for non-parametric values, T-test Anova and Pearson correlation test were also used. Significant statistical correlations between different variables were detected using Chi-square test. The statistical significance correlation reached if $\mathrm{P}$ value less than 0.05 .

\section{RESULTS}

All patients admitted to Suez Fever and General Hospitals during the period from May 2014 till April 2016 with diagnosis of CNS infection were participated in this study, they were 124 patients, the patients were mainly men $71(57.3 \%)$, the mean age was $24.29 \pm 22.94$ years ( ranging from 2 to 72 years). The majority of patients were children $(39.5 \%)$, live in urban areas $(59.7 \%)$ and had low socioeconomic state $(71 \%)$ (Table1).

Regarding final diagnosis and causative organism, nearly half of patients had meningitis, followed by Meningio-Encephalitis and Encephalitis (50.8\%, $27.8 \%$ and $21.8 \%$ respectively). S. pneumoniae was the main causative organism of septic meningitis followed by $H$. influenzae, M. tuberculosis, $N$. meningitides, Cryptococcus neoformans, Enterococci and Staphylococcus aureus (28.2\%,25\%, $13.7 \%, 11.3 \%, 7.3 \%, 3.2 \%, 2.4 \% 1.8 \%$ respectively), while aseptic meningitis represent only $14.5 \%$ of patients (Table 1).

Regarding causative organisms among different age groups, $H$. influenza and $S$. pneumonia were the commonest causative organisms among children, also $S$. pneumonia were the commonest among adolescents and adult, while aseptic and $M$. tuberculosis were mainly infect old age (Fig 2).

The main presenting symptoms were Fever, headache, Neck stiffness, Photophobia and skin Rash $(87.9 \%, 64.5 \%, 55.6 \%, 42.7 \%$ and $16.9 \%$, respectively) (Table 1 ).

The mean duration of hospital admission were $31.19 \pm 24.52$ days and ranging from 2 to 59 days, the longest duration of admission was among $M$. tuberculosis patient's, while the shortest duration of admission was among aseptic meningitis patient's (Table 1).

Regarding morbidity and mortality of causative organisms among studied patients, deafness $(11.4 \%)$ and hydrocephalus $(2.9 \%)$ were the main neurological complications among patients with $H$. influenzae, blindness mainly occurred among patients with $N$. meningitidis (14.3\%), seizures were commonly reported in patients with viral CNS infection, while Hemiplegia (28.6\%) and cranial nerve palsy (14.3\%) were mainly affect patients with $M$. tuberculosis. Brain abscess developed mainly in patients with Staphylococcus aureus (Table 2).

M. tuberculosis associated with highest mortality rates among patients with case fatality (42.86\%), while case fatality was $(8.34 \%)$ among aseptic patients' (Table 2).

Many factors were significantly correlated to high mortality rate, these factors include previous hospital admission, female sex, residency in rural areas, seizures as a presenting symptoms, old age above 60 years, disturbed conscious level and occurrence of neurological complications with relative risk $(4.05,2.4,1.99,1.19,1.260 .91,0.12$ respectively) (Table 3 ).

The mean period from starting of manifestation till hospital admission (the prodromal period) were $5.54 \pm 2.57$ days in died patient, while it was $2.89 \pm 1.43$ in survivors. $85.7 \%$ of died patients were admitted to hospital after one week of illness. Prodromal period was significantly correlated with high mortality, the delayed hospital referral may be attributed to faulty diagnosis with early nonspecific manifestations or trial of hospital management with empirical antibiotics and symptomatic treatment. (Table $3 \& 4$ ). 
Table (1) : Demographic data of the studied groups

\begin{tabular}{|c|c|c|c|c|c|c|}
\hline Pathogens & $\begin{array}{c}S . \\
\text { pneumoniae }\end{array}$ & $\begin{array}{c}H . \\
\text { influenzae }\end{array}$ & $\begin{array}{c}N . \\
\text { meningitidis }\end{array}$ & $\begin{array}{c}M . \\
\text { tuberculosis }\end{array}$ & Others & Viral \\
\hline Patients number & $35(28.2 \%)$ & $31(25 \%)$ & $14(11.3 \%)$ & $17(13.7 \%)$ & $9(7.3 \%)$ & $18(14.5 \%)$ \\
\hline Age Y (Median) ${ }^{*}$ & 6.50 & 5.00 & 44.63 & 25.75 & 24.08 & 17.00 \\
\hline$($ Mean \pm Std $)$ & $17.23 \pm 19.87$ & $15.01 \pm 18.56$ & $36.91 \pm 25.40$ & $35.98 \pm 22.44$ & $31.61 \pm 17.82$ & $29.51 \pm 26.62$ \\
\hline Males & $62.9 \%$ & $62.9 \%$ & $45.2 \%$ & $57.1 \%$ & $64.7 \%$ & $55.6 \%$ \\
\hline Hospital stay (days) & $25.74 \pm 20.28$ & $25.65 \pm 25.21$ & $32.50 \pm 23.88$ & $55.29 \pm 26.27$ & $33.00 \pm 24.34$ & $26.61 \pm 17.87$ \\
\hline Fever & $91.4 \%$ & $93.5 \%$ & $92.9 \%$ & $76.5 \%$ & $88.9 \%$ & $77.8 \%$ \\
\hline Headache & $71.4 \%$ & $48.4 \%$ & $64.3 \%$ & $82.4 \%$ & $66.7 \%$ & $61.1 \%$ \\
\hline Neck stiffness & $60.0 \%$ & $45.2 \%$ & $57.1 \%$ & $76.5 \%$ & $55.6 \%$ & $44.4 \%$ \\
\hline Photophobia & $42.9 \%$ & $35.5 \%$ & $42.9 \%$ & $64.7 \%$ & $33.3 \%$ & $38.9 \%$ \\
\hline Rash & $2.9 \%$ & $22.6 \%$ & $35.7 \%$ & $17.6 \%$ & $11.1 \%$ & $22.2 \%$ \\
\hline Altered consciousness & $25.7 \%$ & $19.4 \%$ & $28.6 \%$ & $47.1 \%$ & $33.3 \%$ & $22.2 \%$ \\
\hline Neurologic complications & $17.1 \%$ & $19.4 \%$ & $14.3 \%$ & $52.9 \%$ & $22.2 \%$ & $16.7 \%$ \\
\hline Rural Residency & $31.4 \%$ & $29.0 \%$ & $57.1 \%$ & $58.8 \%$ & $33.3 \%$ & $50.0 \%$ \\
\hline Low Socioeconomic state & $68.6 \%$ & $67.7 \%$ & $57.1 \%$ & $70.6 \%$ & $66.7 \%$ & $61.1 \%$ \\
\hline Case-fatality rate & $25.81 \%$ & $18.52 \%$ & $16.67 \%$ & $42.86 \%$ & $28.57 \%$ & $8.34 \%$ \\
\hline
\end{tabular}

${ }^{*}$ Age in years expressed in median (means \pm standard deviation), Males expressed in number (percentage)

Case fatality rate $=$ Number of deaths among hospitalized cases of confirmed meningitis due to a specific cause divided by the number of hospitalized patients with the same cause of meningitis

Table (2) : Neurological complications in the studied group

\begin{tabular}{|l|c|c|c|c|c|c|c|}
\hline \multicolumn{1}{|c|}{ Pathogens } & $\begin{array}{c}\text { Tota } \\
\text { I No. }\end{array}$ & $\begin{array}{c}\text { S. } \\
\text { pneumonia } \\
\boldsymbol{e}\end{array}$ & $\begin{array}{c}\boldsymbol{H} . \\
\text { influenzae }\end{array}$ & $\begin{array}{c}\boldsymbol{N} . \\
\text { meningitidi } \\
\boldsymbol{S}\end{array}$ & $\begin{array}{c}\text { M. } \\
\text { tuberculosis }\end{array}$ & Others & Viral \\
\hline Deafness & 5. & $1(4.3 \%)$ & $4(11.4 \%)$ & --- & --- & --- & --- \\
\hline Blindness & 4 & $1(4.3 \%)$ & $1(2.9 \%)$ & $2(14.3 \%)$ & --- & --- & --- \\
\hline Seizures & 4 & $2(8.7 \%)$ & --- & --- & $1(14.3 \%)$ & --- & $1(16.7 \%)$ \\
\hline $\begin{array}{l}\text { Cranial N } \\
\text { Palsy }\end{array}$ & 2 & --- & $1(2.9 \%)$ & --- & $1(14.3 \%)$ & --- & --- \\
\hline Hemiplegia & 2. & --- & --- & --- & $2(28.6 \%)$ & --- & --- \\
\hline $\begin{array}{l}\text { Hydrocephal } \\
\text { us }\end{array}$ & 1 & --- & $1(2.9 \%)$ & --- & --- & -- & -- \\
\hline $\begin{array}{l}\text { Brain } \\
\text { Abscess }\end{array}$ & 1. & --- & --- & --- & --- & $1(12.5 \%)$ & - \\
\hline
\end{tabular}

The subjects are expressed in number and percentage.

Table (3) : Risk factors for death among the studied group

\begin{tabular}{|l|c|c|c|c|}
\hline \multicolumn{1}{|c|}{ Risk factor } & Died** & Survived & Relative Risk & P Value \\
\hline Females & $14(26.4 \%)$ & $39(73.6 \%)$ & 2.40 & $<0.05$ \\
\hline Age above 60 Years & $3(16.7 \%)$ & $15(83.3 \%)$ & 1.19 & $<0.05$ \\
\hline Disturbed conscious level & $7(20.6 \%)$ & $27(79.4 \%)$ & 0.91 & $<0.05$ \\
\hline Seizures & $4(16.0 \%)$ & $38(73.1 \%)$ & 1.26 & $<0.05$ \\
\hline Previous hospital admission & $9(56.3 \%)$ & $7(43.8 \%)$ & 4.05 & $<0.05$ \\
\hline Rural Residency & $14(26.9 \%)$ & $38(73.1 \%)$ & 1.99 & $<0.05$ \\
\hline Presence of neurological complications & $17(60.7 \%)$ & $11(39.3 \%)$ & 0.12 & $<0.05$ \\
\hline Prodromal periods in days** & $5.54 \pm 2.57$ & $2.89 \pm 1.43$ & & $<0.05$ \\
\hline
\end{tabular}

*The subjects are expressed number and percentage.

**The subjects are expressed in means \pm standard deviation, $\mathrm{P}$ Value $=$ statistically significant relation when $\mathrm{P}$ less than 0.05 
Table (4) : Prodromal period in survived and died subgroups

\begin{tabular}{|l|l|c|c|c|c|c|}
\hline \multicolumn{2}{|c|}{ Prodromal period } & First Day & 2-7 Days & $\begin{array}{c}\text { More than a } \\
\text { Week }\end{array}$ & total & $\begin{array}{c}\text { P- } \\
\text { value }\end{array}$ \\
\hline \multicolumn{2}{|l|}{ Total NO } & $13(10.5 \%)$ & $104(83.9 \%)$ & $7(5.6 \%)$ & $124(100 \%)$ & \\
\hline \multirow{2}{*}{ Survived } & Uncomplicated & $10(76.9 \%)$ & $78(75.0 \%)$ & $1(14.3 \%)$ & 89 & \\
\cline { 2 - 7 } & Complicated & $1(7.7 \%)$ & $10(9.6 \%)$ & $0(0.0 \%)$ & 11 & \\
\hline Died & $2(15.4 \%)$ & $16(15.4 \%)$ & $6(85.7 \%)$ & 24 & \\
\hline
\end{tabular}

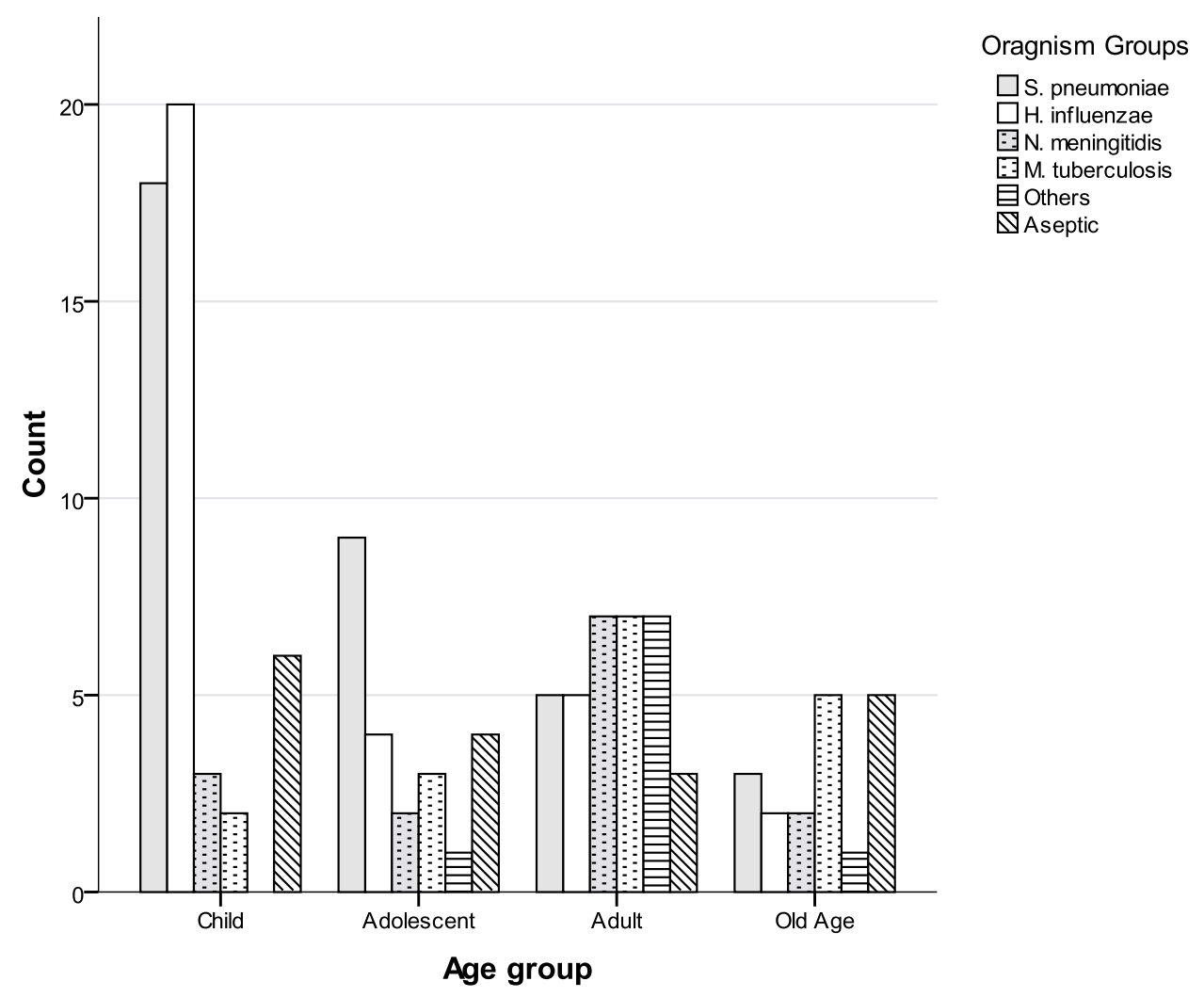

Fig. 1: Frequency of different organism in each patients' group

\section{DISCUSSION}

The reason to carry out this study is to recognize the changes of the pattern of CNS infections among patients in Suez governorate, also to investigate the risk factors for death in those patients and to discover out ways to prevent or to minimize the morbidity and mortality among those patients.

In our study most affected age group was children; these data are in agreement with many previous literature which detect that children are the most vulnerable group to CNS infection [15,17]. Also males are more affected than females which in agreement with Rantakallio et al. who mentioned that $63 \%$ of patients in this cohort study in Finland were male [18].
Most of studied patients live in urban areas $(59.7 \%)$, in contradictory to many researchers who reported that CNS infection was common among rural residency $[\mathbf{9 , 1 9 ]}$. This can be explained by the fact that most of Suez governorate areas are urban. In addition, most of our patients had low socio-economic status (71\%). This result comes in agreement with WHO report 2000 which revealed that septic meningitis was more prominent in the developing countries due to low socioeconomic status which favour poor personal hygiene and sanitation leading to spread of infection [20].

Fever was the main presenting symptoms in our patients, followed by headache, neck stiffness, photophobia, whereas the skin rash was evident only in $16.9 \%$ of patients. This result runs parallel to the result of Zaki et al., 2014 who carried their 
study on 125 cases of CNS infection and reported that the percentage of clinical manifestations among studied patients were fever, headache, stiff neck photophobia, and altered consciousness $(100 \%, 88.5 \%, 80 \%, 75 \%$ and $63 \%$ respectively) [19]. Also, Arada, and his colleagues reported that the percentage of clinical manifestations among studied patients were fever, headache neck stiffness and disturbed consciousness $(79.8 \%, 88.2 \%, 89.9 \%$ and $57.6 \%$ respectively) [21].

The majority of patients were proved to have septic meningitis $(85.5 \%)$, whereas only $14.5 \%$ of cases had aseptic meningitis. This comes in agreement with the results of Zaky and his colleagues, at Imbaba Fever Hospital, who found that the majority of patients had septic meningitis followed by meningio-encephalitis and encephalitis $(50.8 \%, 27.8 \% \& 21.8 \%$ respectively) and only $16 \%$ of patients had aseptic encephalitis [19].

Regarding causative organism $S$. pneumoniae was the main causative organism followed by $H$. influenzae, $M$. tuberculosis, then $N$. meningitidis $(28.2 \%, 25 \%, 13.7 \%$ and $11.3 \%$ respectively), while aseptic meningitis were only reported in (14.5\%) of patients. These results revealed that there is change in the distribution of pathogens that cause CNS infections, in Egypt. Previously Neisseria meningitidis, was the driving cause of meningitis till late 90 s $[\mathbf{8 , 2 2 - 2 4}]$. Nowadays $S$. pneumoniae became the driving cause $[\mathbf{5 , 8 , 2 5 ]}$. These epidemiological changes must be considered when starting empirical treatment of such cases before the appearance of culture results. $H$. influenzae became a driving organism causing meningitis among Egyptian children $[\mathbf{5 , 2 2 , 2 5}]$. This results were in agreement with those reported by Zaky and his colleague. They carried their study on 125 patients with CNS infection admitted in Imbaba Fever Hospital during year 2012, they found that the commonest causative organism among adult patients were $S$. pneumoniae followed by $H$. influenzae, then $N$. meningitides $(38.5 \%, 24 \%$ \& $15.5 \%$ respectively), while $H$. influenzae was the commonest causative organism among children [19].

Mortality rate among studied patients was (19.4\%), while the morbidity rate was $(22 \%)$ in patients with meningitis complicated with neurological sequelae, as sensory or motor affections, cranial nerve dysfunction mainly hearing impairment, disturbed cognitive function and seizures [26].
Seizure was present in $16.7 \%$ of aseptic meningitis patient's and in $8.7 \%$ of meningitis patient's associated with $S$. pneumonia. This result comes in agreement with the result reported by Durand and his colleagues as they found that seizures were common among patients with meningitis secondary to S. pneumonia [27].

Hearing loss commonly occurred in patients infected by $H$. influenza. This finding comes in agreement with many reports in which $H$. influenza was the commonest etiological organism leading to hearing loss among patients with bacterial meningitis [28-30]. This study revealed that blindness was common among patients infected with $N$. meningitides (14.3\%), this comes in agreement with many studies that reported visual impairment in patients with $N$. meningitides, as Scarborough and his colleagues ,2007, reported that $3 \%$ of $N$. meningitides patients developed blindness [31]; optic atrophy was detected among $9 \%$ of patients in the study of Hammad et al. [32]. Also, Beardsley et al., 2016 reported visual affection in $4 \%$ of the studied patients [33].

TB meningitis patient's complicated with Hemiplegia and cranial nerve palsy in $28.6 \%$ \& $14.3 \%$ respectively, this comes in a harmony with the result of Hammad et al. who reported that $30 \%$ of survived patients treated from TB meningitis developed severe neurological complications mainly, hemiparesis,paraplegia, cranial nerve palsy and hydrocephalus [32].

Regarding risk factors, most of previous studies matched with our study which revealed that many factors were significantly correlated to high mortality rate. These factors include previous hospital admission for treatment from the same condition, female sex, residency in rural areas, seizures, disturbed conscious level, occurrence of neurological complications, prolonged prodromal period more than a week $[13,32,34-36]$.

In agreement with many literatures, this study revealed that delayed hospital admission (prolonged prodromal period) carry significant risk of morbidity and mortality among studied patients. This can be explained by delayed identification and diagnosis of the condition or ineffective home management and delayed starting of proper antimicrobial medication before admission [13, 32,34-36. 


\section{CONCLUSION}

CNS infections still carry high morbidity and mortality rates. Early clinical suspicion and diagnosis of CNS infections and immediate management are crucial factors in reduction of morbidity and mortality rates. The changes of causative organisms patterns must be considered for implementation of standard diagnostic and therapeutic approaches to improve outcomes.

\section{Ethical approval}

Consent for an interview was taken from each participant, who was assured about the confidentiality of his information. The faculty of medicine Suez Canal University research ethics committee approved the study

\section{Funding}

None

\section{Conflicts of interest}

There are no conflicts of interest

\section{REFERENCES}

1. Roos KL, Tyler KL. Meningitis, Encephalitis, Brain abscess, and Empyema. In Harrison's Principles of Internal Medicine. 16th ed. New York: McGraw-Hill Professional; 2004. p.2471-90.

2. World Health Organization (WHO). Meningococcal meningitis: Fact sheet 2017 . World Health Organization 17 A.D. December 1 [cited 2017 Sep 19];Available from: URL: http://www. who.int/mediacentre/factsheets/fs141/en/.

3. Kennedy PG. Viral encephalitis. J Neurol. 2005; 252:268-72.

4. Sejvar JJ. The evolving epidemiology of viral encephalitis. Curr Opin Neurol. 2006; 19:350-7.

5. Afifi S, Wasfy MO, Azab MA, Youssef FG, Pimentel G, Graham TW, et al. Laboratory-based surveillance of patients with bacterial meningitis in Egypt (1998-2004). Eur J Clin Microbiol Infect Dis. 2007; 26:331-40.

6. Brouwer MC, Tunkel AR, van de Beek D. Epidemiology, diagnosis, and antimicrobial treatment of acute bacterial meningitis. Clin Microbiol Rev. 2010; 23:467-92.

7. Centers for Disease Control and Prevention (CDC). Bacterial Meningitis 2017. Centers for Disease Control and Prevention 2017 January 25 [cited 2017 Jan 1];Available from: URL: https://www.cdc.gov/meningitis/bacterial.html

8. Girgis NI, Sippel JE, Kilpatrick ME, Sanborn WR, Mikhail IA, Cross E, et al. Meningitis and encephalitis at the Abbassia Fever Hospital, Cairo, Egypt, from 1966 to 1989. Am J Trop Med Hyg. 1993; 48:97-107.
9. Hassan A, Abdel Wahab MF. Bacterial meningitis in U.A.R. J Egypt Public Health Assoc. 1969; 44: 246-52.

10. Abdel-Ghani SM, Hassan EM, Masoud S, Guirgis NI. Rapid diagnosis of bacterial meningitis by latex agglutination test. J Egypt Public Health Assoc. 1989; 64:31-44.

11. Hausdorff WP, Hajjeh R, Al-Mazrou A, Shibl A, Soriano-Gabarro M. The epidemiology of pneumococcal, meningococcal, and Haemophilus disease in the Middle East and North Africa (MENA) region--current status and needs. Vaccine. 2007; 25:1935-44.

12. Gray LD, Fedorko DP. Laboratory diagnosis of bacterial meningitis. Clinical Microbiology Reviews. 1992; 5:130.

13. van de Beek D, Brouwer MC, Thwaites GE, Tunkel AR. Advances in treatment of bacterial meningitis. The Lancet. 2012; 380:1693-702.

14. Logan SAE, MacMahon E. Viral meningitis. BMJ. 2008; 336:36-40.

15. Khetsuriani N, Holman RC, Anderson LJ. Burden of encephalitis-associated hospitalizations in the United States, 1988-1997. Clin Infect Dis. 2002; 35:175-82.

16. Huppatz C, Durrheim DN, Levi C, Dalton C, Williams D, Clements MS, et al. Etiology of encephalitis in Australia, 1990-2007. Emerg Infect Dis. 2009; 15:1359-65.

17. Rasul CH, Zaman MA, Hossain MJ, Nasrin E, Rahman M. Outcome and prognostic factors of acute meningoencephalitis in children of Southern Bangladesh. Sri Lanka Journal of Child Health. 2013; 42:27-32.

18. Rantakallio P, Leskinen M, von WL. Incidence and prognosis of central nervous system infections in a birth cohort of 12,000 children. Scand J Infect Dis. 1986; 18:287-94.

19. Zaky S, Baki A, Farouk S, Sabry S, Saad Deraz A, Sanad M, et al. Presentation, prognostic factors and outcome of acute septic meningitis in an egyptian fever hospital. Ind J Sci Res and Tech. 2014; 2:112-8.

20. WHO. The world health report 2000 - Health systems: improving performance. WHO 2008 Available from: URL: http://www.who.int/whr/ 2000/en/

21. Arda B, Sipahi OR, Atalay S, Ulusoy S. Pooled analysis of 2,408 cases of acute adult purulent meningitis from Turkey. Med Princ Pract. 2008; 17:76-9. 
22. Youssef FG, El-Sakka H, Azab A, Eloun S, Chapman GD, Ismail $\mathrm{T}$, et al. Etiology, antimicrobial susceptibility profiles, and mortality associated with bacterial meningitis among children in Egypt. Ann Epidemiol. 2004; 14:44-8.

23. Boctor WM. Statistical analysis of bacterial meningitis at Embaba Fever Hospital. J Egypt Public Health Assoc. 1969; 44:253-9.

24. Miner WF, Edman DC. Acute bacterial meningitis in Cairo, Arab Republic of Egypt, 1 January 1971 through 31 December 1975. Am J Trop Med Hyg. 1978; 27:986-94.

25. Ministry of Health and Population E. Enhanced Surveillance for Communicable Diseases, annual summary January-December 2000 report. US Department of Defense Global Emerging Infections Surveillance and Response System 2000Available from: URL: http://www.geis. fhp.osd.mil/GEIS/Training/EgyptSurv2000.htm

26. Lucas MJ, Brouwer MC, van de Beek D. Neurological sequelae of bacterial meningitis. $J$ Infect. 2016; 73:18-27.

27. Durand ML, Calderwood SB, Weber DJ, Miller SI, Southwick FS, Caviness VS, et al. Acute Bacterial Meningitis in Adults - A Review of 493 Episodes. N Engl J Med. 1993; 328:21-8.

28. Yeat SW, Mukari SZ, Said H, Motilal R. Post meningitic sensori-neural hearing loss in children: alterations in hearing level. Med J Malaysia. 1997; 52:285-90.

29. Dodge PR, Davis H, Feigin RD, Holmes SJ, Kaplan SL, Jubelirer DP, et al. Prospective evaluation of hearing impairment as a sequela of acute bacterial meningitis. $N$ Engl J Med. 1984; 311:869-74.
30. Damodaran A, Aneja S, Malhotra VL, Bais AS, Ahuja B, Taluja V. Sensorineural hearing loss following acute bacterial meningitis:a prospective evaluation. Indian Pediatr. 1996; 33:763-6.

31. Scarborough M, Gordon SB, Whitty CJM, French N, Njalale Y, Chitani A, et al. Corticosteroids for bacterial meningitis in adults in sub-Saharan Africa. N Engl J Med. 2007; 357:2441-50.

32. Hammad OM, Hifnawy TMS, Omran DAH, Zaki $\mathrm{S}$, Daraz A. Gram-negative bacillary meningitis in Egypt. The Journal Of The Egyptian Public Health Association. 2011; 86.

33. Beardsley J, Wolbers M, Kibengo FM, Ggayi AB, Kamali A, Cuc NTK, et al. Adjunctive Dexamethasone in HIV-Associated Cryptococcal Meningitis. N Engl J Med. 2016; 374:542-54.

34. Bedford H. Prevention, treatment and outcomes of bacterial meningitis in childhood. Prof Nurse. 2001 Oct;17(2):100-2. Review. PubMed PMID: 12030056.

35. Auburtin M, Wolff MF, Charpentier JF, Varon E FAU - Le Tulzo Y, Le Tulzo YF, Girault CF, et al. Detrimental role of delayed antibiotic administration and penicillin-nonsusceptible strains in adult intensive care unit patients with pneumococcal meningitis: the PNEUMOREA prospective multicenter study. Crit Care Med. 2006 Nov;34(11):2758-65. PubMedPMID: 16915106.

36. Koomen I, Grobbee DE FAU - Roord J, Roord JJ FAU - Donders R, Donders RF, JennekensSchinkel AF, van Furth AM. Hearing loss at school age in survivors of bacterial meningitis: assessment, incidence, and prediction. Pediatrics. $2003 \quad$ Nov;112(5):1049-53. PubMed PMID:14595044. 